\title{
Short and Long Term Outcomes After Simultaneous Resection of Colorectal Malignancies and Synchronous Liver Metastases: Reply
}

\author{
Eduardo de Santibañes • Diego Fernández • \\ Ernesto Molmenti
}

Published online: 7 December 2010

(C) Société Internationale de Chirurgie 2010

We thank Drs. Glantzounis and Katsios for their valuable observations.

We have to state, however, that our findings are similar to those of other investigators. Martin et al. [5] reported that simultaneous resections had fewer complications (49 vs. $67 \% ; P=0.01)$, shorter median hospital stays (10 vs. 18 days; $P=0.01$ ), and similar mortality rates ( 2.2 vs. $2.8 \% ; P=\mathrm{NS}$ ) when compared to staged procedures. Moreover, when comparing patients who underwent major liver resections (lobectomy or more), those with simultaneous surgeries had a lower morbidity rate $(60$ vs. $70 \%$; $P=0.03$ ), shorter operating times, decreased hospital stays, and a twofold decrease in laparotomy complications. Capussotti et al. [2, 3] and Martin et al. [5] reported that the combined morbidity was greater after staged procedures than after simultaneous resections, with no difference in mortality. Martin et al. [5] reported no difference in severe morbidities. A recent metanalysis by Chen et al. [4] and a multicenter study by Brouquet et al. [1] showed that simultaneous resections (when feasible) were associated with improved morbidity and mortality, diminished use of blood products, and equivalent long-term oncologic benefit. Continuous improvements in biomarkers as well as chemotherapy regimens will allow for improved results, both in simultaneous resections and in staged resections.

E. de Santibañes $(\bowtie) \cdot$ D. Fernández

General Surgery and Liver Transplant Unit, Hospital Italiano de

Buenos Aires, Gascón, C1181ACH Buenos Aires, Argentina

e-mail: eduardo.desantibanes@hospitalitaliano.org.ar

E. Molmenti

Department of General Surgery, North Shore Long Island Jewish

Health System, 300 Community Drive Manhasset,

New York, NY 11030, USA
Until a prospective randomized study is carried out, all studies will suffer to a greater or lesser extent from the potential drawbacks outlined in the letter from Glantzounis and Katsios. However, it is our hope that they will consider the mounting evidence in support of simultaneous resection of colorectal metastases.

\section{References}

1. Brouquet A, Mortenson MM, Vauthey JN et al (2010) Surgical strategies for synchronous colorectal liver metastases in 156 consecutive patients: classic, combined or reverse strategy? J Am Coll Surg 210:934-941

2. Capussotti L, Ferrero A, Vigano L et al (2007) Major liver resections synchronous with colorectal surgery. Ann Surg Oncol 14:195-201

3. Capussotti L, Vigano L, Ferrero A et al (2007) Timing of resection of liver metastases synchronous to colorectal tumor: proposal of prognosis-based decisional model. Ann Surg Oncol 14:1143-1150

4. Chen J, Li Q, Wang C et al (2010) Simultaneous vs. staged resection for synchronous colorectal liver metastases: a metaanalysis. Int J Colorectal Dis. July 29 [Epub ahead of print]

5. Martin R, Paty P, Fong Y et al (2003) Simultaneous liver and colorectal resections are safe for synchronous colorectal liver metastasis. J Am Coll Surg 197:233-241 discussion 241-242 